\title{
Variação das massas de gordura e proteína corporal e dos órgãos viscerais de cabras Alpinas nos 60 dias de lactação
}

\author{
Variation of masses of body fat and protein and visceral organs of alpine goats in the \\ first 60 days of lactation
}

\section{OLIVEIRA, Tadeu Silva de ${ }^{{ }^{*}}$; RODRIGUES, Marcelo Teixeira ${ }^{1}$; LIMA, Magna Coroa ${ }^{1}$; VIEIRA, Ricardo Augusto Mendonça ${ }^{2}$; OLIVEIRA, Vinicio Sanches de ${ }^{1}$; ALVES, Tiago Martins Oliveira ${ }^{1}$}

\author{
${ }^{1}$ Universidade Federal de Viçosa, Centro de Ciências Agrárias, Departamento de Zootecnia, Viçosa, \\ Minas Gerais, Brasil. \\ ${ }^{2}$ Universidade Estadual Norte Fluminense, Departamento de Ciência Animal, Campos dos Goytacazes, \\ Rio de Janeiro, Brasil. \\ *Endereço para correspondência: tadeusilva@zootecnista.com.br
}

\section{RESUMO}

Objetivou-se mensurar a movimentação das massas de gordura e proteína corporal, além de quantificar as massas dos órgãos e vísceras de cabras Alpinas ao longo das oito semanas de lactação. Foram utilizadas 51 cabras multíparas da raça Alpina, alocadas em baias metabólicas individuais. As cabras foram distribuídas em um delineamento inteiramente casualizado, com oito tratamentos e seis repetições, sendo os tratamentos constituídos pelas semanas de lactação. Foram realizados abates sequenciais de seis cabras por semanas de lactação para mensuração das massas de gordura e proteína, e também o peso dos órgãos e vísceras. Ocorreu redução significativa na massa dos tecidos proteico e adiposo, porém de forma adversa, sendo que o tecido proteico foi mobilizado com maior intensidade nas primeiras duas semanas pós-parto, já a o tecido adiposo uma queda de forma constante. Não houve efeito sobre peso do fígado, rúmen, omaso, abomaso e intestino grosso, mas ocorreu redução nos pesos do intestino delgado, útero e glândula mamária. As cabras Alpinas nas três semanas pós-parto mobilizam não apenas gordura, mas também proteína corporal para atender a demanda de produção de leite. Somente o intestino delgado, útero e glândula mamária tiveram seus pesos afetados com as oito semanas de lactação.

Palavras-chave: cabras, mobilização, tecido adiposo, tecido protéico

\section{SUMMARY}

This study aimed to measure the changes of masses of body fat and protein, and also quantify the masses of organs and viscera of Alpine goats throughout the eight weeks of lactation. We used 51 multiparous Alpine goats, allocated in individual metabolic pens. The goats were distributed in a completely randomized design with six replications and eight treatments, and the treatments by weeks of lactation. Slaughters were carried sequential six goats per week of lactation to measure the mass of fat and protein, as well as the weight of the organs and viscera. Significant reduction in mass and adipose tissue protein, but adversely, and the tissue protein was mobilized with greater intensity in the first two weeks postpartum, since the fat falling steadily. There was no effect on liver weight, rumen, omasum, abomasum and large intestine, but there was a reduction in the weights of the small intestine, uterus and mammary gland. The Alpine goats within three weeks postpartum mobilize not just fat, but also body protein to meet the demand of milk production. Only the small intestine, uterus and mammary gland shown weight affected with eight weeks of lactation.

Keywords: adipose tissue, goats, mobilization, protein tissue 


\section{INTRODUÇÃOO}

O estudo das partes não integrantes da carcaça (órgãos, vísceras, cabeça, pele, sangue, patas, e gorduras viscerais) é importante, pois tendem a variar de acordo com a raça, idade, sexo, estádio fisiológico e a alimentação. Assim, o conhecimento das mudanças nas massas dos órgãos e vísceras no período de lactação de cabras se torna de extrema relevância, pois reflete diretamente nas suas necessidades em energia e proteína para a manutenção das atividades basais.

A exigência de energia para mantença é tida como o consumo de oxigênio do corpo, sendo a metade dessas necessidades utilizada pelas paredes do trato gastrintestinal e fígado para absorção e metabolismos de nutrientes digeridos, um terço pela pele, rins e tecido nervoso e o restante para as atividades musculares básicas (SEAL; REYNOLDS, 1993; OLIVEIRA et al. 2011). Isto porque tecidos associados com a digestão, como trato gastrintestinal e o fígado, além dos pulmões, coração e glândula mámaria, têm uma maior atividade metabólica e consequentemente têm maior exigência de energia que o músculo esquelético que consome cerca de $23 \%$ da energia (MACITELLI et al., 2005). Para Maior Junior et al. (2008) a massa de órgãos e vísceras pode influenciar a eficiência alimentar do animal e a utilização dos nutrientes por vários tecidos do corpo.

Assim como vacas e ovelhas a extensão da perda de massa corporal em cabras no pós-parto varia amplamente e pode ser afetada por diversos fatores. Entretanto a mobilização de energia e proteína para cabras nos primeiros 40 dias de lactação ainda não estão totalmente esclarecidos, sendo que o AFRC (1998) considera um decréscimo de 4,6MJ de EM/dia e 30g PM/dia no primeiro mês de lactação, baseado num valor constante de perda, $1 \mathrm{~kg} / \mathrm{semana}$ de peso vivo proposto pelo (INRA, 1988). O valor constante da mobilização de energia e proteína considerado pelo INRA (1988) e o AFRC (1998) não reflete de forma fidedigna a dinâmica de mobilização das massas de gordura e proteína. Assim é imprescindível conhecer a magnitude com que a fase de balanço energético negativo influencia na perda de massa de gordura e de proteína em cabras.

Diante do exposto, objetivou-se mensurar a movimentação das massas de gordura e proteína corporal, além de quantificar as massas dos órgãos e vísceras de cabras Alpinas ao longo das oito semanas de lactação.

\section{MATERIAL E MÉTODOS}

O experimento foi conduzido no setor de caprinocultura da Universidade Federal de Viçosa. O clima predominante na cidade de Viçosa (MG) é o tropical de altitude do tipo Cwa (inverno seco e verão chuvoso), pela classificação de Köeppen.

Foram utilizadas 51 cabras multíparas da raça Alpina oberhasli, com peso médio inicial de 57,2 $\pm 8,5 \mathrm{~kg}$, com uma produção média de leite na lactação anterior de $1,89 \pm 0,5 \mathrm{~kg}$, alocadas em baias metabólicas individuais providas de cochos para fornecimento das rações e água à vontade. A seleção desses animais foi a partir de um lote inicial composto de 250 cabras de forma a proporcionar maior homogeneidade entre as unidades experimentais. Foi utilizado um delineamento inteiramente casualizado com oito semanas de lactação (tratamentos) e seis repetições, 
em que, cada semana de lactação foram abatidas seis cabras.

Todos os animais receberam uma dieta experimental sendo formulada para cabras em lactação com peso médio de $50 \mathrm{~kg}$ e uma produção média de $3,0 \mathrm{~kg}$ de leite de acordo com os valores preconizados pelo NRC (2007), como exposto na Tabela 1. A ração foi fornecida duas vezes ao dia $(7 \mathrm{~h}$ e às 16h) sempre após a ordenha dos animais e ajustada diariamente para aproximadamente $20 \%$ de sobras. Antes da oferta matinal, as sobras de cada unidade experimental foram coletadas, pesadas, registradas e amostradas, em seguida armazenadas sob congelamento $\left(-10^{\circ} \mathrm{C}\right)$ juntamente com amostras da silagem de milho e do concentrado, formando-se posteriormente uma amostra composta semanal por animal, que ao final do período experimental formaram uma amostra composta total por animal/tratamento, para determinar a composição química do alimento.

Foi realizado um ensaio de digestibilidade no $23^{\circ}$ dia experimental utilizando-se seis cabras lactantes, sendo que as cabras que foram utilizadas no ensaio estavam com o mesmo período de lactação (23 dias de lactação). No ensaio foi utilizado um delineamento inteiramente casualizado com uma dieta experimental e seis repetições. Os animais foram alocados em gaiolas metabólicas para ensaio de metabolismo, o qual permite a separação de fezes e urina. Após um período de adaptação de 21 dias, foram feitas coletas totais das fezes durante cinco dias consecutivos, sendo coletadas a cada duas horas. As amostras das fezes foram devidamente identificadas e armazenadas em freezer a $-20^{\circ} \mathrm{C}$. As amostras da silagem de milho, concentrado, sobras e fezes do período do ensaio foram présecadas a 55 e a $60^{\circ} \mathrm{C}$ em estufa de ventilação forçada, durante 72 horas, processadas em moinho tipo Willey com peneiras de malha de $1 \mathrm{~mm}$ e acondicionadas individualmente, em frascos de vidro, à temperatura ambiente.

Tabela 1. Ingredientes e composição química da dieta consumida pelas cabras em lactação

\begin{tabular}{|c|c|}
\hline Ingredientes & $\%$ \\
\hline Silagem de Milho & 41,5 \\
\hline Fubá de Milho & 25,7 \\
\hline Farelo de Soja & 15,6 \\
\hline Farelo de Trigo & 12,4 \\
\hline Óleo & 2,2 \\
\hline Calcário Calcítico & 1,1 \\
\hline Bicarbonato de Sódio & 1,0 \\
\hline Sal Comum & 0,4 \\
\hline \multicolumn{2}{|l|}{ Composição química } \\
\hline MS & 61,7 \\
\hline $\mathrm{PB}$ & 14,0 \\
\hline FDN & 26,5 \\
\hline FDA & 14,2 \\
\hline LIGNINA & 1,8 \\
\hline PIDN (\% PB) & 7,1 \\
\hline PIDA (\% PB) & 6,9 \\
\hline $\mathrm{EE}$ & 5,9 \\
\hline CINZAS & 5,8 \\
\hline $\mathrm{CNF}$ & 48,2 \\
\hline $\mathrm{Ca}$ & 3,1 \\
\hline $\mathrm{P}$ & 1,7 \\
\hline \multicolumn{2}{|c|}{ Valor de energia disponível } \\
\hline NDT (\%) & 82,88 \\
\hline EM (Mcal/kg) & 2,90 \\
\hline EL (Mcal/kg) & 1,89 \\
\hline \multicolumn{2}{|c|}{$\begin{array}{l}\text { MS = matéria seca, } \mathrm{PB}=\text { proteína bruta, } \\
\text { FDN = fibra em detergente neutro, FDA = fibra } \\
\mathrm{em} \text { detergente ácido, PIDN = proteína insolúvel } \\
\mathrm{em} \mathrm{detergente} \mathrm{neutro,} \mathrm{PIDA} \mathrm{=} \mathrm{proteína} \\
\text { insolúvel em detergente ácido, EE = extrato } \\
\text { etéreo, CNF = carboidratos não fibrosos, } \\
\mathrm{Ca}=\text { cálcio, } \mathrm{P}=\text { fósforo, NDT = nutrientes } \\
\text { digestíveis totais, EM = energia metabolizável, } \\
\mathrm{EL}=\text { energia líquida. }\end{array}$} \\
\hline
\end{tabular}


Foram coletadas amostras diárias e armazenadas em freezer a $-20^{\circ} \mathrm{C}$, durante o ensaio de digestibilidade, no final deste período, foi feita uma amostragem dessa, no qual resultou em uma amostra composta de cada material (fezes, silagem de milho, concentrado e sobras) que foi utilizada para determinação do extrato etéreo (EE, obtido pela diferença entre o peso do balão vazio e o balão + EE, após a extração com éter dietílico, pelo aparelho de extração Soxhlet por $6 \mathrm{~h}$; AOAC, 1990), proteína ( $\mathrm{N}$, analisada via micro Kjeldahl utilizando 0,3 g de amostra; AOAC, 1990) e cinzas (completa combustão na mufla a $600^{\circ} \mathrm{C}$ por 6h; AOAC,1990), fibra em detergente neutro (FDN) (VAN SOEST et al., 1991), já os carboidratos não fibrosos (CNF) foram calculados como $\mathrm{CNF}=100-(\% \mathrm{~PB}+\% \mathrm{EE}+\%$ Cinzast $\% \mathrm{FDN}$ (MERTENS, 1997).

O teor de NDT foi calculado através do $(\mathrm{PB}$ ingerida $-\mathrm{PB}$ fecal $)+(\mathrm{FDN}$ ingerido $-\mathrm{FDN}$ fecal $)+(\mathrm{CNF}$ ingerido $-\mathrm{CNF}$ fecal $)+[2,25 \times($ EE ingerido EE fecal)].

Os valores de energia digestível (ED) e energia metabolizável (EM) utilizandose as equações sugeridas pelo NRC (2001).

$\mathrm{ED}(\mathrm{Mcal} / \mathrm{kg})=$

$(\mathrm{CNFd} / 100) \times 4,2+(\mathrm{FDNd} / 100) \times 4,2+(\mathrm{PB}$ $\mathrm{d} / 100) \times 5,6+(\mathrm{EEd} / 100) \times 9,4-0,3$

A transformação de ED para EM foi feita segundo a equação:

$\mathrm{EM}(\mathrm{Mcal} / \mathrm{kg})=1,01 \times \mathrm{ED}(\mathrm{Mcal} / \mathrm{kg})-0,45$

A conversão de NDT para EL foi feita utilizando-se a equação do NRC (2001):

$\mathrm{EL}(\mathrm{Mcal} / \mathrm{kg})=0,0245 \times \mathrm{NDT}(\%)-0,12$

As cabras foram ordenhadas duas vezes ao dia (às 6h30 e às 15h30), a produção de leite dos animais foi mensurada por meio de pesagens diárias e individuais do leite. Os animais passaram por pesagens semanais, para acompanhamento da perda ou ganho de peso, um dos indicativos de mobilização ou retenção de reservas corporais.

Foram realizados abates sequenciais de seis cabras por semanas de lactação para mensuração inicial da massa de gordura e proteína e determinação do peso dos órgãos e vísceras. Sendo que um grupo de três cabras foi abatido logo após o parto para estimação da massa de gordura e proteína e determinação do peso dos órgãos e vísceras dos animais que permaneceram no experimento (grupo referência), os demais abates foram realizados com o decorrer da lactação ( $7^{\circ}$ dia ao $56^{\circ}$ dias de lactação). As cabras foram abatidas seguindo os procedimentos de abate humanitário. Após a insensibilização por atordoamento, foi realizada a sangria através da secção das veias jugulares e carótidas, todo o sangue foi colhido e pesado. Em seguida, foi removida a glândula mamária, que foi pesada e dissecada. Posteriormente, feita a esfola e a separação da carcaça quente e dos órgãos internos e vísceras (fígado com a vesícula biliar, rins, coração, pâncreas, baço, língua, pulmão, diafragma, esôfago, traqueia, bexiga e o útero, sendo que a bexiga assim como a vesícula biliar foi pesada cheia e vazia). A gordura interna foi separada em gordura omental e gordura visceral (gorduras mesentéricas, perirenal e pericárdica). O trato gastrintestinal (rúmen-reticulo, omaso, abomaso, intestino delgado e intestino grosso, foram pesados cheios e vazios), cabeça/patas e a pele. Todas as partes foram pesadas e colocadas em sacos plásticos previamente identificados $\mathrm{e}$ congelados a $-15^{\circ} \mathrm{C}$.

Em seguida, a carcaça e o conjunto cabeça/patas foram serrados em serra elétrica, e logo após levadas para moagem no equipamento tipo Cutter (30HP; 1775rpm), sendo moídas 
separadamente. Vísceras/órgãos/sangue e glândula mamária também foram moídas no Cutter, separadamente, já a pele foi levada para moagem no moinho de bola para posteriores análises químicas.

$\mathrm{O}$ peso de corpo vazio (PCV) foi determinado pela diferença do peso corporal ao abate e o conteúdo do TGI.

As amostras compostas de vísceras/órgãos/sangue, carcaça, cabeça/patas e glândula mamária foram acondicionados em bandejas de alumínio com capacidade de $500 \mathrm{ml}$ e liofilizadas por um período entre 48 a 72 horas, para determinação da matéria seca gordurosa (MSG).

Posteriormente, as amostras foram submetidas a lavagens sucessivas com éter de petróleo durante 24 horas, obtendo-se a matéria seca prédesengordurada (MSPD). A gordura removida no pré-desengorduramento foi calculada pela diferença entre a MSG e a MSPD, cujo resultado foi adicionado aos obtidos para o extrato etéreo residual na MSPD, para determinação do teor total de gordura. Em seguida, as amostras foram moídas em moinho de bola, para posteriores determinações da matéria seca, nitrogênio total, extrato etéreo, conforme AOAC (1990).

As variáveis foram analisadas segundo o seguinte modelo estatístico:

$\mathrm{y}_{\mathrm{ij}}=\mu+\tau_{\mathrm{i}}+\mathrm{e}_{\mathrm{ij}}$

No qual $\mathrm{y}_{\mathrm{ij}}$ representa o logaritmo natural do valor medido no j-ésimo animal na i-ésima semana de lactação, $\mu$ representa a média geral, $\tau_{\mathrm{i}}$ corresponde à i-ésima semana de lactação, e $\mathrm{e}_{\mathrm{ij}}$ representa o erro aleatório. Seis cabras $(\mathrm{j}=1,2, \ldots, 6)$ foram abatidas em cada semana de lactação. Todavia, para testar a hipótese de ocorrência de variâncias heterogêneas em dados longitudinais, foram testadas duas estruturas de variâncias, isto é, variâncias homogêneas e variâncias heterogêneas sendo verificada a verossimilhança de cada estrutura de variâncias. Além de considerar os $P$-values para os efeitos linear, quadrático e cúbico, foi ainda verificada a verossimilhança dos modelos linear, quadrático e cúbico. A verossimilhança das estruturas de variâncias e a qualidade de ajuste dos modelos foram avaliadas segundo os critérios utilizados por Vieira et al. (2012). O modelo estatístico foi ajustado aos dados por meio do procedimento MIXED dos SAS version 9 (SAS Institute, 1999). As variáveis preditas foram apresentadas na escala original, isto é, $\hat{\mathrm{Y}}_{\mathrm{i} .}=\exp \left(\hat{\mathrm{y}}_{\mathrm{i} .}\right)$. Foram considerados outliers os dados com resíduo estudentizado fora dos intervalos de $(-2$, +2 ) conforme critério descrito Draper e Smith (1996).

\section{RESULTADOS E DISCUSSÃO}

A Tabela 2 apresenta os efeitos das variáveis, consumo de matéria seca, produção do leite em função dos dias de lactação, já o peso e composição corporal dos animais em função das semanas de lactação.

No consumo de matéria seca houve um aumento $(\mathrm{P}<0,001)$ expressivo durante os primeiros 30 dias de lactação, logo após este período o consumo tendeu a estabilizar-se (Figura 1a). O consumo voluntário de matéria seca está correlacionado negativamente com as reservas corporais no pós-parto visto em muitos estudos com a espécie bovina (ROCHE \& STOCKDALE, 2002), na espécie ovina (PARIZOTTO JUNIOR et al., 2012) e na espécie caprina (RODRIGUES et al., 2007). Essa correlação negativa pode ser justificada pela utilização mais rápida de substratos lipogênicos (ácidos graxos não esterificados - AGNE) e acúmulo de 
triglicerídeos no fígado das fêmeas que estão mobilizando de forma mais intensa suas reservas corporais. Assim, quando o fluxo de AGNE está elevado, o centro da saciedade no hipotálamo é ativado, provocando a redução do consumo de alimentos. Já as fêmeas que estão mobilizando pouca reserva ou estão depositando reservas corporais, ocorre menor fluxo de AGNE no sangue, estimulando com isso o maior consumo de alimento nas fêmeas que estão perdendo peso (ALLEN et al., 2009).

A produção de leite aumentou $(\mathrm{P}<0,001)$ com o avançar da lactação (Figura 1b). Até o pico de lactação, período que compreende aproximadamente entre a sexta e a oitava semana de lactação, a cabra apresenta-se em balanço energético negativo, ocorrendo, assim, redução da massa corporal (Figura 1c), uma perda em média $5 \mathrm{~kg}$ neste trabalho, devido à ingestão insuficiente de nutrientes (Figura 1a) necessários para manter a crescente produção de leite e sua manutenção (EKNAS et al., 2006). Não houve diferença no peso final dos animais $(\mathrm{P}>0,005)$. No entanto, houve variação no peso dos animais (Figura 1c) $(\mathrm{P}<0,0005)$ ao longo das oito semanas de lactação, isso devido ao aumento na produção de leite (Figura 1b), sendo que apesar do aumento no consumo de matéria seca (Figura 1a) pelos animais provavelmente não ocorreu um aporte de nutriente que suportasse tal produção, fazendo com que houvesse mobilização de reservas corporais. Porém, para Dunshea, Bell \& Trigg (1990) e o AFRC (1998), apenas a variação na massa corporal dos animais não fornece uma informação conclusiva sobre as mudanças na composição corporal dos animais.

No peso de corpo vazio (PCVZ) das cabras houve decréscimo $(\mathrm{P}<0,001)$ no decorrer das oito semanas da lactação (Figura 1d), sendo que esta acontece de forma constante nas cinco primeiras semanas de lactação. Até o pico de lactação, período que compreende aproximadamente da sexta a oitava semana de lactação, a cabra apresentase em balanço energético negativo, ocorrendo com isso uma redução da massa corporal (Figura 1d), devido à ingestão insuficiente de nutrientes necessários para manter a crescente produção de leite e sua manutenção (EKNAS et al., 2006).

Tabela 2. Valor de $\mathrm{P}$ dos efeitos lineares (L), quadrático (Q) e cúbico (C) para o consumo de matéria seca, produção de leite, peso vivo e vazio, variação do peso e composição corporal

\begin{tabular}{lccc}
\hline \multirow{2}{*}{ Variáveis } & \multicolumn{3}{c}{ Semanas de Lactação } \\
\cline { 2 - 4 } & $\mathrm{L}$ & $\mathrm{Q}$ & $\mathrm{C}$ \\
\hline CMS $(\mathrm{g} / \mathrm{d})$ & 0,004 & $<0,001$ & 0,158 \\
Produção de Leite $(\mathrm{kg} / \mathrm{d})$ & $<0,001$ & 0,379 & 0,765 \\
PV final $(\mathrm{kg})$ & 0,513 & 0,136 & 0,302 \\
Variação do Peso Corporal $(\mathrm{kg})$ & 0,0005 & 0,433 & 0,254 \\
PCVZ (kg) & 0,071 & $<0,001$ & 0,036 \\
Massa de Tecido Adiposo $(\mathrm{kg})$ & $<0,001$ & 0,437 & 0,067 \\
Massa de Tecido Proteico $(\mathrm{kg})$ & $<0,001$ & 0,032 & 0,016 \\
\hline
\end{tabular}

$\overline{\mathrm{CMS}}=$ consumo de matéria seca, $\mathrm{PV}$ final = peso vivo final das cabras em cada abate, $\mathrm{PCVZ}=$ peso de corpo vazio. 

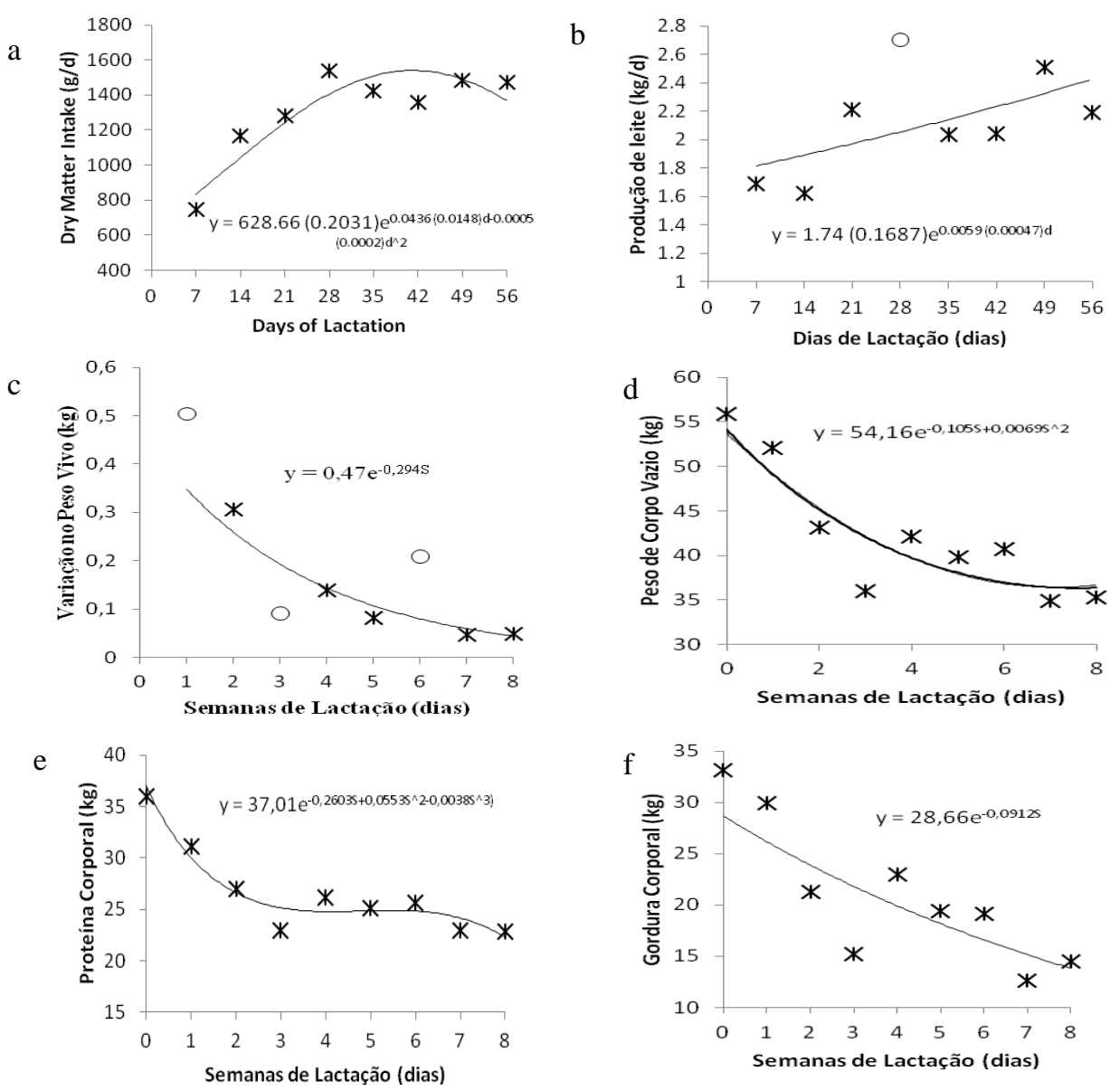

Figura1. Consumo de matéria seca (a), Produção de leite (b), Variação do peso (c), Peso corporal vazio (d), Massa de tecido proteico (e), Massa de tecido adiposo (f) de cabras Alpinas nas oito primeiras semanas de lactação, sendo o (o) considerado outliers

Ocorreu redução $(\mathrm{P}<0,001)$ na massa dos tecidos proteico e adiposo, porém de forma adversa, sendo que o tecido proteico (Figura 1e) foi mobilizado com maior intensidade nas primeiras três semanas pós-parto, tendo uma desaceleração dessa mobilização em seguida. Para Bell (1995) o músculo esquelético serve como um "pool" de aminoácidos que serão utilizados para suportar o aumento da gliconegênese durante o início da lactação, além de ajudar na produção das imunoglobulinas IgG, IgA e IgM no colostro na primeira semana e para síntese deste nutriente no leite, fazendo com que ocorra uma mobilização de proteína muscular para atender a esta demanda proteica, já que o consumo deste está limitado nesta fase (LIMA et al., 2009). Ngwa et al. (2009) observaram um decréscimo na massa corporal de cabras alpinas na fase inicial da lactação, corroborando com os dados encontrados neste trabalho.

A massa do tecido adiposo (Figura 1f) no momento do parto e no início da lactação é muito importante, pois minimiza a mobilização de proteína dos tecidos, porém, foi observado $(\mathrm{P}<0,001)$ uma queda de forma constante, apesar da gordura ter uma variação muito instável. Ngwa et al. (2009) observaram 
uma redução na massa de gordura interna de cabras no início de lactação. Da mesma forma, Eknas et al. (2006) observou uma diminuição constante da massa de tecido adiposo de cabras leiteiras norueguesas de 11-125 dias de lactação (ex. 7,35 para $3,87 \mathrm{~kg}$ ).
Não houve diferença $(\mathrm{P}>0,05)$ para peso do fígado, rúmen, omaso, abomaso e intestino grosso, podendo ser devido à alta mobilização do tecido adiposo (principalmente da gordura interna) e do tecido proteico (principalmente da carcaça), polpando assim estes orgãos.

Tabela 3. Valor de $\mathrm{P}$ dos efeitos lineares $(\mathrm{L})$, quadrático $(\mathrm{Q})$ e cúbico $(\mathrm{C})$ para o peso dos órgãos e vísceras, expresso em $\mathrm{kg}$

\begin{tabular}{lccc}
\hline \multirow{2}{*}{ Variáveis } & \multicolumn{3}{c}{ Semanas de Lactação } \\
\cline { 2 - 4 } & $\mathrm{L}$ & $\mathrm{Q}$ & $\mathrm{C}$ \\
\hline Fígado $(\mathrm{kg})$ & 0,797 & 0,084 & 0,987 \\
Rúmen $(\mathrm{kg})$ & 0,761 & 0,472 & 0,539 \\
Omaso $(\mathrm{kg})$ & 0,531 & 0,898 & 0,494 \\
Abomaso (kg) & 0,303 & 0,841 & 0,517 \\
Intestino Delgado $(\mathrm{kg})$ & 0,295 & 0,032 & 0,344 \\
Intestino Grosso $(\mathrm{kg})$ & 0,892 & 0,307 & 0,078 \\
Útero $(\mathrm{kg})$ & $<0,001$ & $<0,001$ & 0,869 \\
Glândula Mamária $(\mathrm{kg})$ & 0,016 & $<0,001$ & 0,4094 \\
\hline
\end{tabular}

Durante a fase de balanço energético negativo há uma tendência de redução no tamanho dos órgãos internos em relação ao peso corporal, sendo o fígado e o trato gastrintestinal os mais afetados, todavia, principalmente no inicio da lactação, estes órgãos são os mais ativos metabolicamente $\mathrm{e}$ juntamente com os rins e o coração são responsáveis por cerca de 40 a $50 \%$ da energia de mantença destes animais (SEAL; REYNOLDS, 1993; OLIVEIRA et al., 2011). Gerassev et al. (2008) relatou que o crescimento de órgãos como o fígado e o trato digestivo implicam em rápidas mudanças de peso, quando o animal recebe dieta acima da mantença, e apresenta notável atrofia, quando recebem alimentação abaixo da mantença. Os mesmos autores verificaram que os pesos do fígado, rúmen, omaso, abomaso e intestinos, regrediram seu peso em resposta à restrição do fornecimento de proteína bruta e energia da dieta.

$\mathrm{O}$ intestino delgado (Figura 2a) nas primeiras quatro semanas sofreu um aumento do peso e em seguida uma redução deste $(\mathrm{P}<0,032)$, isto devido sua maior atividade metabólica neste período (GERASSEV et al., 2008) em razão do consumo de matéria seca (Figura 1a), em seguida houve uma redução do seu peso, este resultado evidencia que a desaceleração do consumo de matéria seca dos animais afetou diretamente o metabolismo dos intestinos, os mesmos reduziram suas massas a fim de se adequaram a quantidade de energia e proteína bruta.

$\mathrm{Na}$ cabra, o processo de involução uterina é rápido durante as duas primeiras semanas seguintes ao parto, isso porque envolve processos 
fisiológicos simultâneos como redução do tamanho do útero, perda de tecidos, reparação do tecido residual e diminuição do fluido tissular (LOOPER; LENTS; WETTMANN, 2003) (Figura 2b). Para Degefa,
Ababneh e Moustafa (2006) a redução do peso e na espessura da parede do útero ocorre rapidamente até o sétimo dia pós-parto, em seguida, ocorre uma queda mais lenta.
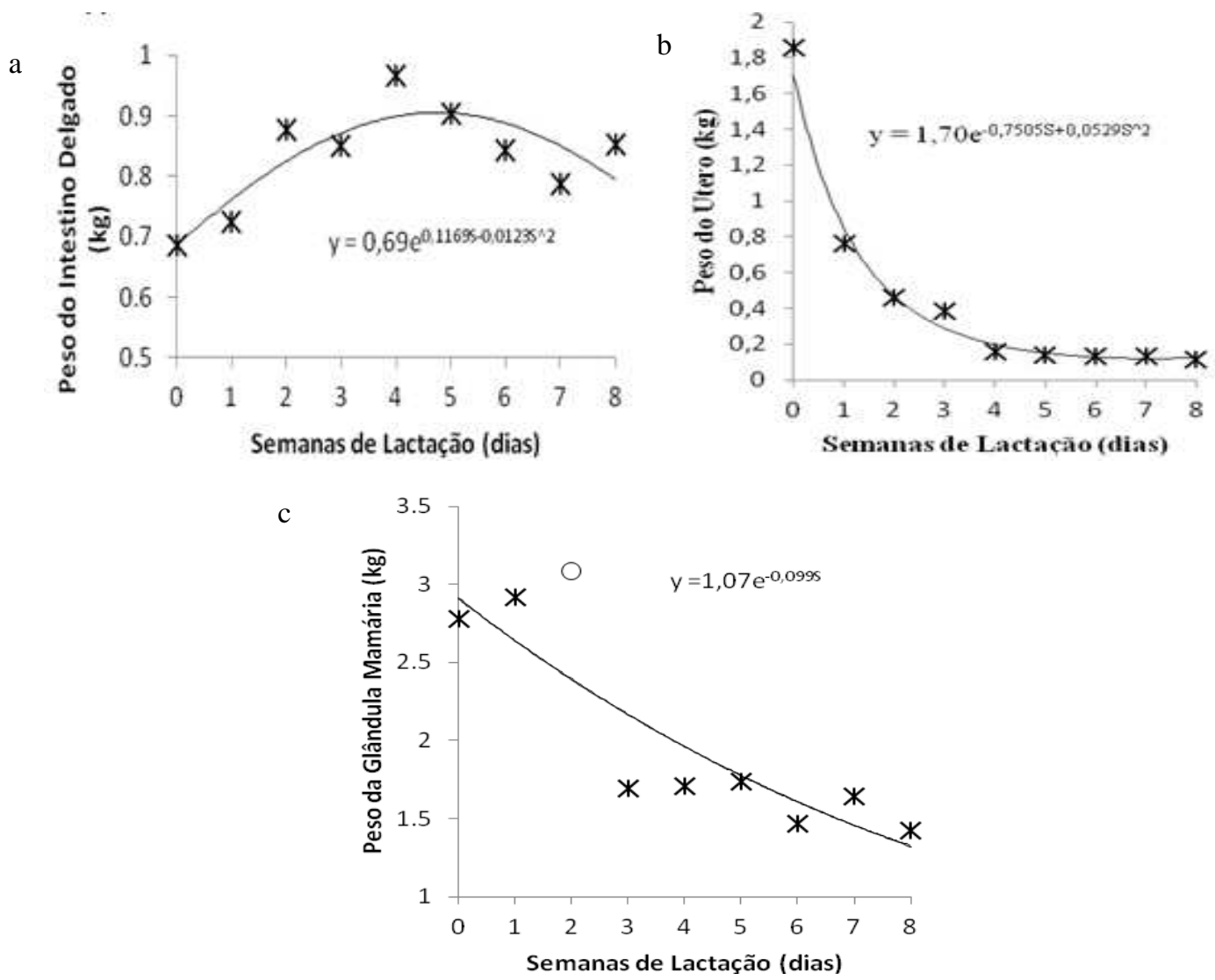

Figura 2. Peso do intestino delgado (a), Peso do útero (b), Peso da glândula mamária (c) de cabras Alpinas nas oito primeiras semanas de lactação, sendo o (o) considerado outliers.

A regeneração do endométrio está ligada ao tipo de placenta em espécies que possuem placenta cotiledonária, como ocorre nos ruminantes. De acordo com Looper, Lents e Wettmann (2003), os úteros das espécies ruminantes levam cerca de quatro a cinco semanas para involuir.

A glândula mamária reduziu seu peso (Figura 2c) - $(\mathrm{P}<0,001)$ durante as oito semanas de lactação, este fato pode estar associado à alta demanda energética nesta fase e tendo como consequência menor aporte energético devido o consumo estar sendo afetado pela ação de hormônios somatotropina, catecolaminas, tiroxina, que estimulam de forma direta ou indiretamente a liberação de AGNE no sangue, ativando o centro da saciedade no hipotálamo, provocando a redução do consumo. Nessa fase de balanço energético negativo, o NRC (2001) cita que os animais estão em catabolismo, isto é, 
fase em que estão mobilizando nutrientes. Assim, possivelmente, houve uma perda do peso deste órgão também com o avançar da lactação.

Neste contexto podemos inferir que cabras alpinas nas três semanas pósparto mobilizam não apenas gordura, mas também proteína corporal para atender a demanda de produção de leite. As oito semanas de lactação não influenciaram o peso do fígado, rúmen, omaso, abomaso e intestino grosso. Porém o intestino delgado, útero $\mathrm{e}$ glândula mamária tiveram seus pesos afetados.

\section{REFERÊNCIAS}

AGRICULTURAL AND FOOD

RESEARCH COUNCIL (AFRC). The

Nutrition of Goats. Technical

committee on response to nutrients.

Wallingford, UK: CAB International, 1998.

AKAIKE, H. A new look at the statistical model identification. IEEE transactions on automatic control, v.19, p.716-723, 1974.

ALLEN, M.S.; BRADFORF, B.J.; OBA, M. The hepatic oxidation theory of the control of feed and its application to ruminants. Journal of Animal

Science, v.87, p.3317-3334, 2009.

ASSOCIATION OF OFFCIAL

ANALYTICAL CHEMICAL - AOAC.

Official methods of analysis. $15^{\text {th }}$.

Washington: Association of Official

Analysis Chemists, 1990.

BELL, A.W. Regulation of organic nutrient metabolism during transition from late pregnancy to early lactation. Journal of Animal Science, v.73, p.2804-2819, 1995.
DEGEFA, T.; ABABNEH, M.M.; MOUSTAFA, M.F. Uterine involution in the post-partum Balady goat. Veterinarki arhiv, v.76, n.2, p.119133, 2006.

DRAPER, N.; SMITH, H. Applied regression analysis. New York: John Wiley and Sons, 1996. 709 p.

DUNSHEA, F.R.; BELL, A.W.; TRIGG, T.E. Body composition changes in goats during early lactation estimated using a two-pool model of tritiated water kinetics. Brirish Journal of Nutrition, v.64, p.121-131, 1990.

EKNAS, M.; KOLSTAD, K.; VOLDEN, H.; HOVE, K. Changes in body reserves and milk quality throughout lactation in dairy goats.

Small Ruminant Research, v.63, n.1, p.1-11, 2006.

GERASSEV, L.C.; PEREZ, R.R.O.; PEDREIRA, B.C.; QUINTÃO, F.A.; OLIVEIRA, R.P. Efeito da restrição alimentar pré e pós-natal sobre o crescimento dos órgãos internos de cordeiros Santa Inês. Arquivo Brasileiro de Medicina Veterinária e Zootecnia, v.60, n.4, p.960-969, 2008.

INSTITUT NATIONAL DE LA RECHERCHE AGRONOMIQUE INRA. Alimentation of bovines, ovins and caprins: nutrition of cattle, sheep and goats. Paris: INRA, 1988. 475p.

JAINUDEEN, M.R.; HAFEZ, E.S.E. Distúrbios reprodutivos nas fêmeas. In: HAFEZ, E.S.E. Reprodução Animal. 6.ed. São Paulo: Manole, 1995. p. 265290.

LIMA, A.L.; PAULETTI, P.; SUSIN, I.; MACHADO NETO, R. Flutuação das variáveis séricas em cabras e estudo comparativo as absorção de anticorpos 
em cabritos recém-nascidos utilizando colostro bovino e caprino. Revista

Brasileira de Zootecnia, v.38, n.11, p.2211-2217, 2009.

LOOPER, M.L.; LENTS, C.A.; WETTMANN, R.P. Body condition at parturition and postpartum weight changes do not influence the incidence of short-lived corporal luteal in postpartum beef cows. Journal of Animal Science, v. 81, p.2390-2394, 2003.

MACITELLI, F.; BERCHIELLI, T.T.; SILVEIRA, R.N.; ANDRADE, P.; LOPES, A.D.; SATO, K.J.; BARBOSA, J.C. Biometria da carcaça e peso de vísceras e de órgãos internos de bovinos mestiços alimentados com diferentes volumosos e fontes proteicas. Revista Brasileira de Zootecnia, v.34, n.5, p.1751-1762, 2005.

MAIOR JUNIOR, R.J.S.; CARVALHO, F.F.R.; BATISTA, A.M.V.; VASCONCELOS, R.M.J.; SILVA, R.C.B.; FIGUEIREDO, M.A.S.

Rendimento e características dos componentes não-carcaça de ovinos alimentados com rações baseadas em cana-de-açúcar e uréia. Revista

Brasileira de Saúde e Produção Animal [online], v.9, n.3, p.507-515, 2008.

MERTENS, D.R. Creating a system for meeting the fiber requirements of dairy cows. Journal of Dairy Science, v.80, n.7, p.1463-1481, 1997.

NATIONAL RESEARCH COUNCIL NRC. Nutrient requirements of small ruminants. Washington: National Academy Press, 2007.

NATIONAL RESEARCH COUNCIL NRC. Nutrient requirements of dairy cattle. Washington: National Academy Press, 2001.
NGWA, A.T.L.; DAWSON, J.; PUCHALA, R.; DETWEILER, G.; MERKEL, R.C.; WANG, Z.; TESFAI, K.; SAHLU, T.; FERRELL, C.L.; GOETSCH. A.L. Effects of stage of lactation and dietary forage level on body composition of Alpine dairy goats. Journal of Dairy Science, v.92, p.3374-3385, 2009.

OLIVEIRA, I.M.; PAULINO, P.V.R.; VALADARES FILHO, S.C.; DETMANN, E.; PAULINO, M.F.; GOMIDE, L.A.M.; DUARTE, M.S.; COUTO, V.R.M. Carcass traits of Nellore, F1 Simmental x Nellore and F1 Angus x Nellore steers fed at maintenance or ad libitum with two concentrate levels in the diet. Revista Brasileira Zootecnia, v.40, n.12, p.2938-2946, 2011.

PARIZOTTO JUNIOR, N.; MARÇAL, W.S.; BALARIN, M.S.; ORTUNHO, V.V. Desempenho produtivo e reprodutivo de ovelhas santa inês suplementadas com cromo orgânico durante a estação de monta e a gestação. Archives of Veterinary Science, v.17, n. 1, p.52-59, 2012.

ROCHE, J.R.; STOCKDALE, C.R. A review of the energy and protein nutrition of dairy cows through their dry period and its impact an early lactation performance. Australian Journal of Agricultural, v.53, n.7, p.737-753, 2002.

RODRIGUES, C.A.F.; RODRIGUES, M.T.; BRANCO, R.H.; CARVALHO, G.R.; TORRES, R.A.; TORRES FILHO, R.A. Avaliação do consumo e de metabólitos plasmáticos de cabras gestantes, com duas condições corporais, alimentadas com dietas apresentando diferentes níveis de energia. Revista Brasileira de Zootecnia, v.36, p.945-952, 2007. 
SEAL, C.J.; REYNOLDS,C.K.

Nutritional implications of

gastrointestinal and liver metabolism in ruminants. Nutrition research review, v.6, p.185-208, 1993.

STATISTICAL ANALYSIS SYSTEM - SAS. SAS/STAT user's guide.

Version 9.1. Cary: SAS Institute inc., 1999.

Van SOEST, P.J.; ROBERTSON, J.B.; LEWIS. B.A. Methods for dietary fiber, neutral detergent fiber, and nonstarch polysaccharides in relation to animal nutrition. Journal of Dairy Science, v.74, p.3583-3597, 1991.
VIEIRA, R.A.M.; CAMPOS, P.R.S.S.; SILVA, J.F.C.; TEDESCHI, L.O.;

TAMY, D.W.P. Heterogeneity of the digestible insoluble fiber of selected forages in situ. Animal feed science and technology, v.171, p.154-166, 2012.

Data de recebimento: 08/01/2013

Data de aprovação: 27/11/2013 